\title{
PREVALENCE OF INTESTINAL PARASITIC PROTOZOAN INFECTIONS AMONG FEMALE HIV/AIDS PATIENTS ATTENDING AMINU KANO TEACHING HOSPITAL, KANO, KANO STATE, NIGERIA
}

\author{
${ }^{* 1}$ Dogara, M. M., ${ }^{2}$ Aliyu, A. A. and ${ }^{2}$ Yahaya, A. \\ ${ }^{* 1}$ Department of Biological Sciences, Faculty of Science, Federal University, Dutse, Jigawa State \\ ${ }^{2}$ Dpartment of Biology, Faculty of Science, Kano University of Science, Wudil, Kano State \\ *Corresponding author: mmdodogara@yahoo.com, musadogara2013@gmail.com
}

\begin{abstract}
Intestinal protozoan parasites are the major cause of morbidity and mortality killing millions of patients with HIV/AIDS each year; causing diarrhea especially in infants and immunocompromised people worldwide. HIV infection has been modifying both the epidemiology and outcome of parasitic infections. The aim of this study was to determine the prevalence of intestinal parasitic protozoan infections among women patients with HIV/AIDS attending Aminu Kano Teaching Hospital (AKTH), Kano from October - December, 2016. Stool samples from 82 HIV/AIDS women patients were analyzed for protozoan parasite using direct wet mount, formol-ether concentration techniques and modified Ziehl-Neelson staining techniques whereas the blood samples collected were analyzed for CD4+ T-cell estimation using flow cytometry. Sociodemographic variables were collected by using questionnaire. Chi-square test was used to test the associations between CD4+ $T$-cell count and protozoan infections. $A$ total of three (3) protozoan parasites were encountered among the HIV- positive individuals. These include Giardia intestinalis (33.4\%), Entamoeba histolytica (27.8\%) and E. coli (22.2\%). The result indicated that the parasitic infection with Giardiaintestinalis was significantly higher among HIV-positive women (P>0.05). The age group with the highest prevalence was that of 40-49 years (29.2\%). There was no significant difference in the prevalence of intestinal parasitic protozoan infection with regard to age, CD4+ count, job type of the patients $(P>0.05)$ but there was a significant association between the residence area, pregnancy status and intestinal parasitic protozoan infection $(P<0.05)$. Prevalence was also significantly higher in the rural areas (39.1\%) than in the urban areas (11.4\%). Routine screening for intestinal parasites in HIV-positive patients among others are advocated in the study area.
\end{abstract} Keywords: AKTH; CD4+ count; HIV/AIDS; Immunocompromised; Intestinal Protozoa; Prevalence.

\section{INTRODUCTION}

All over the world, the prevalence of Human Immunodeficiency Virus (HIV)/Acquired Immune Deficiency Syndrome (AIDS) has became a stumbling stone in progress of human civilization and is a huge concern for people worldwide. According to UNAID and WHO joint report, an estimated 35.3 million people were living with HIV globally at the end of 2012 with 69\% of these persons living in Sub-Saharan Africa (UNAIDS/WHO, 2013). Studies conducted in Nigeria revealed 2.6 million people were infected, out of which 1.6 million are women of childbearing age between 15-49 years (Bawa, 2005). Most people living with HIV or at risk for HIV do not have access to prevention, care, and treatment, and there is still no cure (Borle and Patil, 2015).

Intestinal parasites are commonly occurring in children, the aged and in immunocompromised people living in poor sanitation region. Intestinal protozoans are frequently transmitted by unhygienic habits that include direct transfer of ova or cysts to mouth, eating with unwashed hands, eating and drinking of contaminated food and drink and poor sanitary conditions (Ramakrishnan et al., 2007; Richard and Pearson, 2016). Intestinal parasitic infection has been a major source of morbidity in tropical countries especially among HIV patients (Kaplan et al., 1996; Okodua et al., 2003). It has been postulated that colonization of the intestinal tract by parasites may be influenced by enteropathy induced by infection with HIV (Sher et al., 1992; Weber et al., 1992) and that the gut of HIV infected individuals may not be a favourable environment for the establishment and or survival of extracellular parasites but intracellular and mucosal dwelling protozoans (Hunter et al., 1992; Weber et al., 1992).

Human Immunodeficiency Virus (HIV) following its mechanism of infection causes immune suppression in host body that leads to the exposure to a variety of microbial and parasitic attacks (Singh et al., 2013). Besides, infections (opportunistic or not) are globally prevalent (OMS, 1987) but incidences are far more in developing countries with account of $95 \%$ than only $50 \%$ in developed countries (Haileeyesus and Petros, 2009). HIV infection with total 57.9 million victims is a worldwide problem of today. The national prevalence rate of HIV is $3.6 \%$ and Kano State has a prevalence rate of $3.1 \%$.Co-infection with opportunistic and/or non-opportunistic gastrointestinal parasitic infection is common and is almost universal in these patients. 
However, their frequency varies with risk factors and the geographical origin of patients (Alyoune and Biadillah, 1991). It is necessary to understand the impact of them on severity or progression of HIV/AIDS and intervention in the efficacy of applied therapies like anti-retroviral (ARVs) and others.

There are limited number of reports (Fisseha et al., 1998; Kaptcheu and Alekwa, 2000; Adesiji et al., 2007; Yahaya et al., 2013; Jegede et al., 2014) from Nigeria that have described the relationship between HIV and intestinal parasites. In spite of the high HIV/AIDS patients in Nigeria, maternal HIV coinfections with intestinal protozoan infections have been least studied area of HIV research in Nigeria. Only few relevant field-epidemiological investigations have been reported. In Kano State, a few reports exist on the prevalence and impact of intestinal protozoan infections in HIV-Positive female patients. Hence, the present study was designed to further document the prevalence of protozoa species in HIVSero-positive female patients in order provide useful information that could prompt health policy makers to develop intervention for this category of patients.

\section{MATERIALS AND METHODS \\ The Study Area}

This research work was conducted at Aminu Kano Teaching Hospital (AKTH), which is located within Tarauni Local Government Area of Kano State, Nigeria. Tarauni covers an area extending between Latitude $11^{\circ} 58^{\prime} \mathrm{N}$ and Latitude $11^{\circ} 59^{\prime} \mathrm{N}$ as well as between Longitude $8^{\circ} 33^{\prime} \mathrm{E}$ and Longitude $8^{\circ} 35^{\prime} \mathrm{E}$, respectively (Olofin, 2008) and has a population of 21, 224 (NPC, 2006). AKTH is a federal government tertiary health institution that trains Bayero University, Kano medical students and postgraduate physicians as well as providing healthcare services in basically all aspects of curative medicine.

\section{Research Design and Study Population}

The design is cross sectional in approach aimed at documenting the prevalence of intestinal protozoa in HIV/AIDS positive women patients attending AKTH. The study population was HIV positive women patients attending AKTH. The inclusion criteria were women patients who were HIV-positive, with or without signs of diarrhoea, willing to participate in the study and had ability to comprehend the importance of the study. Women patients included in the study consisted of pregnant and non-pregnant women. The distribution of the participant was done using simple random sampling. The exclusion criteria were those on specific antihelminthics or who had any treatment for intestinal parasitism in the last two weeks preceding specimen collection and those who had antacid in the last two weeks preceding specimen collection were all excluded from the study because the drugs could have killed or inhibit reproduction of the parasites. The use of medications such as antacids can distort protozoa morphology contributing to the difficulty in identifying the organism. The study group included the HIV-positive patients with diarrhoea and the control group included the HIV positive patients without any abdominal complain.

\section{Ethical Consideration}

The ethical committee of the Aminu Kano Teaching Hospital (AKTH) approved the study design and the research via a letter AKTH/MAC/SUB/12A/P3/VI/1875. Professional ethics were adopted to ensure effective and proficient conduct of the research. To this end, an informed consent was sought from a cross section of participating HIV positive women attending Aminu Kano Teaching Hospital (AKTH), Kano as well as their right to decline participation in the study before inclusion in the study and prior to collection of clinical samples (stool) from them. This was done with the aid of a consent form. For those of age below 18 years, the consent form was filled by their parents before recruiting them into the study. All personal and medical information of the participants was treated strictly confidential.

\section{Sample Collection and Analysis}

Stool Sample Collection and Analysis

Single stool samples were collected from each participant into sterile wide mouth screw cap labeled containers and analyzed within 24 hours of collection. The cysts and trophozoites of Entamoeba histolytica and Giardia lamblia were detected using direct wet mount method with normal saline $(0.85 \% \mathrm{NaCl}$ solution). The thin smear of slides were prepared and observed for the presence of motile trophozoites under light microscope using $\mathrm{X} 10$ and $\mathrm{X} 40$ magnification. In the concentration procedure by means of an applicator stick, about $1 \mathrm{~g}$ of preserved stool sample was placed in clean $15 \mathrm{ml}$ conical centrifuge $7 \mathrm{ml}$ formalin. The sample dissolved and mixed thoroughly with applicator stick. The resulting suspension was filtered through a sieve (cotton gauze) into a beaker and the filtrate poured back into the same tube. The debris trapped on the sieve was discarded. $3 \mathrm{ml}$ of diethyl ether was added to the mixture and hand shaken, the content was centrifuged at $2000 \mathrm{rpm}$ for 3 minutes. The supernatant poured away and the tube replaced in its rack. Lugol Iodine was used to stain the sediments. A few drops of the stained sediment was placed on clean, free grease slide covered with a cover slip was systematically examined under X10 and X40 objective lenses for the presence of cysts of $G$. lamblia and $E$ coli (Cheesbrough, 2006).

To detect cysts and oocyst of Cryptosporidium parvum, and Isospora belli direct and concentration smears were prepared. From the fresh faecal sample collected from patients, thin smears were prepared, air dried, fixed with methanol for 5 minutes and stained by Zeihl-Neelsen technique. The same procedure was used for smears prepared after concentration. In this technique the slides were stained with Carbol Fuschin for 30 minutes and thereafter washed with tap water. The slides were decolorized in acid alcohol for 1 minute and counter stained with methylene blue for 1 minute. The stained smears were examined microscopically under X40 and X100 magnifications. 
Blood Sample Collection and Analysis

Analysis of blood for CD4 count was done by taking five millilitres of venous blood samples aseptically drawn into labelled EDTA tubes and mixed properly to avoid blood clots. CD4 count was carried out within six hours of sample collection by flow cytometry method using PARTEC Cyflow as recommended by (Assefa et al. 2009). The procedure involved placing $20 \mathrm{ml}$ of CD4 PE antibody into a Partec test tube and $20 \mathrm{ml}$ of well-mixed whole EDTA blood was added, mixed gently and incubated in the dark for 15 minutes at room temperature. The mixture was then agitated during incubation after every 5 minutes. A further eight hundred micro liters $(800 \mu \mathrm{L})$ of CD4 buffer would be added to the mixture of antibody and sample, and mixed gently. This would then be plugged to the counter for counting (Yahaya et al., 2013). The prevalence of intestinal parasitic infection was correlated with CD4 T cell counts of the patients as recommended by Assefa et al. (2009).

\section{METHOD OF DATA ANALYSIS}

The results obtained from the stool specimens were presented in tables in form of frequencies and percentages. Chi-square test was used to determine the relationship between prevalence of intestinal parasitic protozoa and age; association between prevalence of intestinal parasitic protozoa and CD4+ count; relationship between parity and intestinal parasitic protozoan; and relationship between intestinal parasitic Protozoan and occupation. The results were statistically significant if the $p$-value was less than 0.05 and vice-versa.

\section{RESULTS}

The overall prevalence of intestinal parasites protozoan among the HIV/AIDs women patients as shown in Table 1, 2 and 3 was 18 (22.0\%). A total of 3 protozoan parasites were encountered among the HIV- positive individuals. These include Giardia intestinalis (33.4\%), Entamoeba histolytica (27.8\%) and $22.2 \%$ for Entamoeba coli (Fig. 1). Infection with intestinal protozoa appears to increase with age peaking at 40 - 49 year age group. However, the difference in infection between the different age groups was not significant $(P>0.05)$.

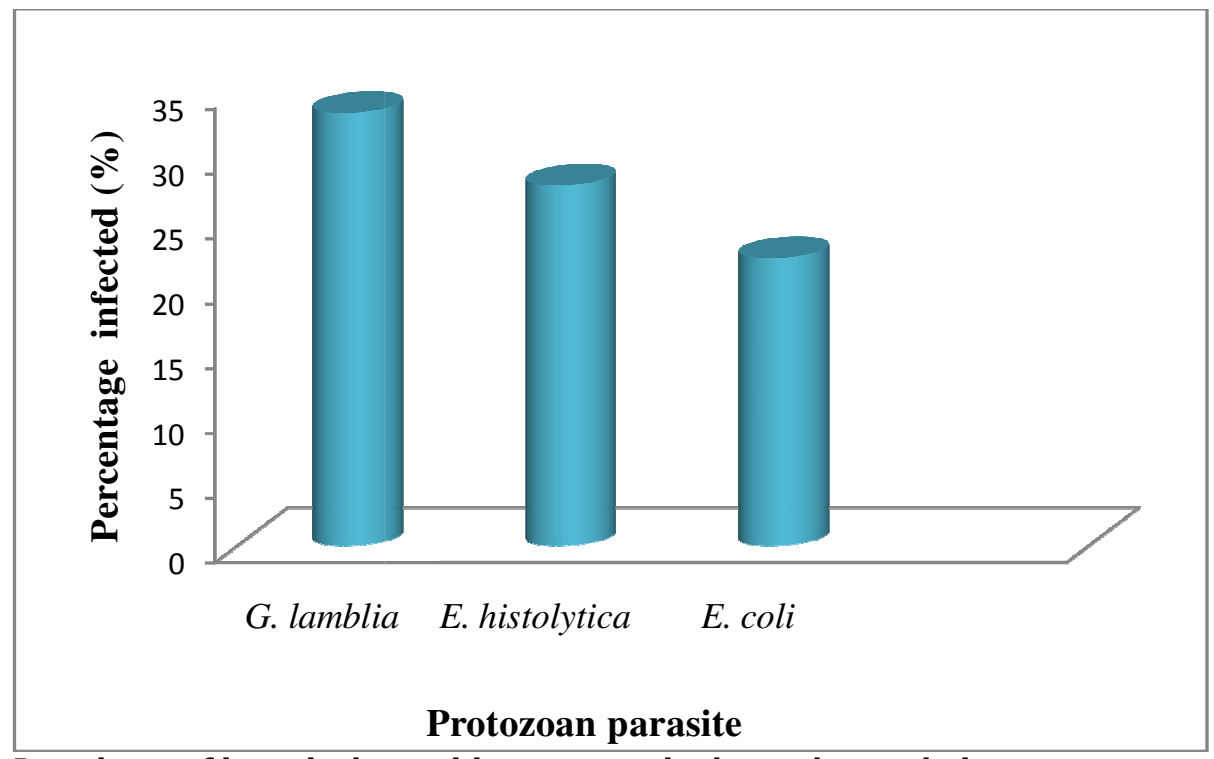

Figure 1: Prevalence of intestinal parasitic protozoan in the study population

Table 1: Distribution of intestinal parasitic protozoan among HIV/AIDS women patients according to age in the study area

\begin{tabular}{lccc}
\hline Age (Years) & No. Examined & No. (\%) Infected & No. (\%)Uninfected \\
\hline $10-19$ & 3 & $0(0.0 \%)$ & $3(100 \%)$ \\
$20-29$ & 15 & $3(20.0 \%)$ & $12(80.0 \%)$ \\
$30-39$ & 40 & $8(20.0 \%)$ & $32(80.0 \%)$ \\
$40-49$ & 24 & $7(29.2 \%)$ & $17(70.8 \%)$ \\
\hline \multicolumn{1}{l}{ Total } & $\mathbf{8 2}$ & $\mathbf{1 8 ( 2 2 . 0 \% )}$ & $\mathbf{6 4 ( 7 8 . 0 \% )}$ \\
\hline$X^{2}{ }_{0.05}$ calculated value $=1.742, X^{2}{ }_{0.05}$ table value=7.815
\end{tabular}

From the result in Table 2 below, the prevalence of intestinal protozoa among HIV women revealed that 5 $(38.5 \%)$ with CD4 count $<200 \mathrm{~mm}^{3}$ had the highest infection rate than those with $\mathrm{CD} 4>200 \mathrm{~mm}^{3}$ that had $13(18.8 \%)$. However, the differences among the two groups showed that it was not significant $(P>0.05)$. 
Bajopas Volume 10 Number 2 December, 2017

Table 2: Prevalence of intestinal parasitic protozoan among HIV/AIDS women patients in relation to CD4+ count in the study area

\begin{tabular}{|c|c|c|c|}
\hline CD4+ Count & No. Examined & No. (\%) Infected & No. (\%) Uninfected \\
\hline $\begin{array}{l}>200 \mathrm{cell} / \mathrm{mm}^{3} \\
<200 \mathrm{cell} / \mathrm{mm}^{3}\end{array}$ & $\begin{array}{l}69 \\
13 \\
\end{array}$ & $\begin{array}{r}13(18.8 \%) \\
5(38.5 \%)\end{array}$ & $\begin{array}{r}56(81.2 \%) \\
8(61.5 \%)\end{array}$ \\
\hline Total & 82 & $18(22.0 \%)$ & $64(78.0 \%)$ \\
\hline
\end{tabular}

In Fig. 2, the prevalence of intestinal parasitic protozoan infections among HIV/AIDS women patients according to occupation revealed that housewives had the highest infection $11(29.7 \%)$ followed by students with $3(25.0 \%)$ and least was among the civil servants $1(11.1 \%)$. There was no significant difference between the prevalence of parasitic protozoan infections based on occupations $(P>0.05)$.

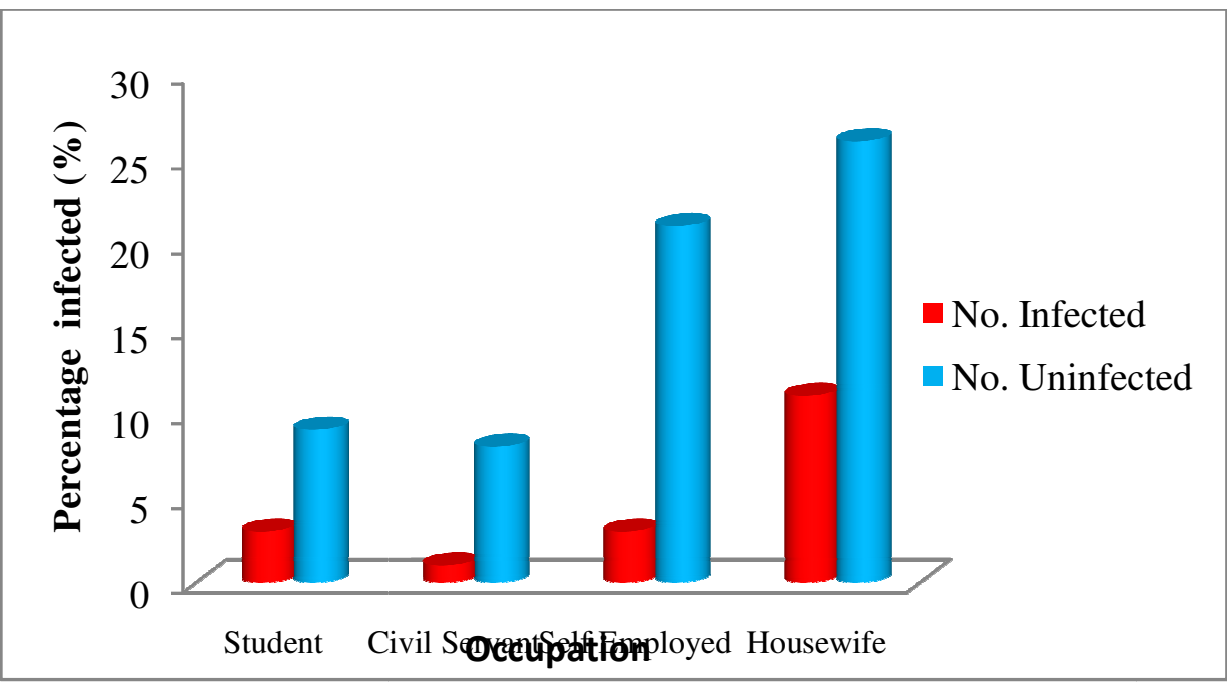

Figure 2: Prevalence of intestinal parasitic protozoan among HIV/AIDS women patients according to occupation in the study area

From the results in Fig. 3, the prevalence of intestinal parasitic protozoan among HIV/AIDS women patients according to place residency showed that those that reside in rural areas had the highest prevalence of 9 (39.1\%) followed by those in semi urban areas with 5
(20.8\%) and the lowest was among those that reside in urban areas with $4(11.4 \%)$. There was significant difference between infection rate and places of residency $(P<0.05)$.

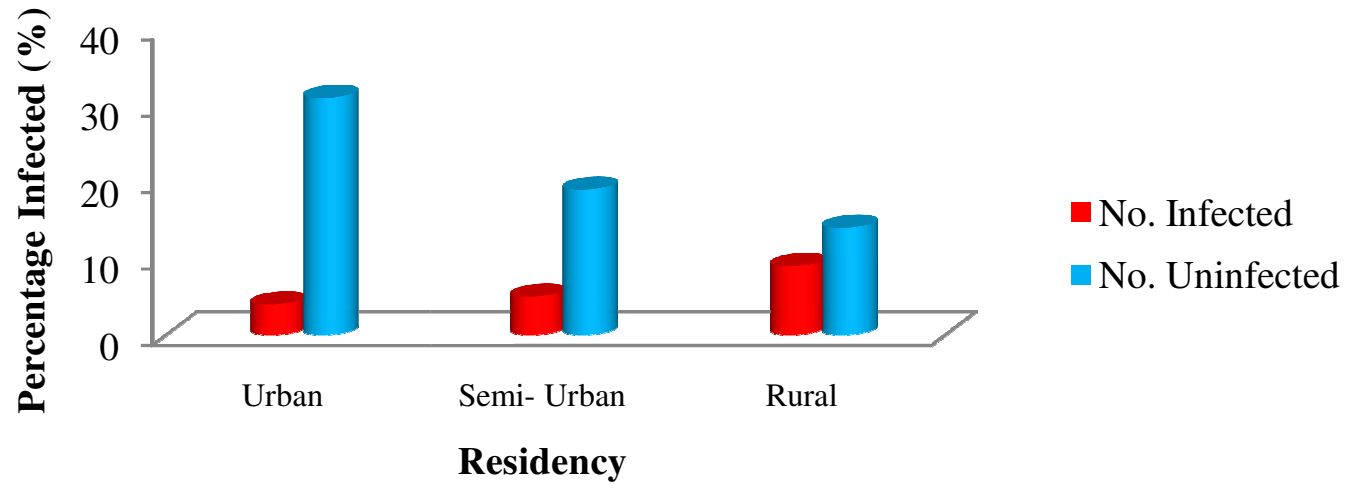

Figure 3: Prevalence of intestinal parasitic protozoan among HIV/AIDS women patients according to place of residency in the study area

In Table 3, the prevalence of intestinal parasitic protozoan infections among HIVAIDS women patients revealed that pregnant women had higher prevalence of $6(66.7 \%)$ than those without pregnancy with the infection rate of $12(16.4 \%)$. The chi- square test of significant showed that there was a significant difference in infection rate between the two groups $(P<0.05)$. 
Bajopas Volume 10 Number 2 December, 2017

Table 3: Prevalence of intestinal parasitic protozoan infections among HIV/AIDS women patients according to pregnancy status in the study area

\begin{tabular}{lccc}
\hline Pregnancy Status & No. Examined & No. (\%) Infected & No. (\%) Uninfected \\
\hline Pregnant & 9 & $6(66.7 \%)$ & $3(33.3 \%)$ \\
Non-pregnant & 73 & $12(16.4 \%)$ & $61(83.6 \%)$ \\
\hline \multicolumn{1}{l}{ Total } & $\mathbf{8 2}$ & $\mathbf{1 8 ( 2 2 . 0 \% )}$ & $\mathbf{6 4 ( \mathbf { 7 8 . 0 } \% )}$ \\
\hline $\mathrm{X}^{2}{ }_{0.05}$ calculated value $=11.567, \mathrm{X}^{2}{ }_{0.05}$ table value $=3.841$ & &
\end{tabular}

\section{DISCUSSION}

Intestinal protozoan infections are increasingly becoming prevalent in AIDS patients (Shah et al., 2005). Almost $80 \%$ of AIDS patients die of AIDSrelated infections including intestinal parasites rather than of the HIV infection itself (Kelly, 1998). Intestinal parasitic infections are a major cause of morbidity and mortality in HIV infected patients in Nigeria. This study had determined the prevalence of intestinal parasitic protozoan infections among HIV/AIDS women patients in the study area.

The high prevalence $(22.0 \%)$ of intestinal parasitic protozoan among HIV female patients in this study is in consistent with similar studies carried out in Adamawa State, Nigeria (Alo et al., 1993; Akogun and Badaki, 1998) and in Abuja, Nigeria by Udeh et al. (2008) who reported $22.8 \%$ of parasitic protozoan and almost in conformity to those reported in Ethiopia (Teklemariam et al., 2013). In contrast, other studies have reported lower prevalence of $9.5 \%$ in Jos, Plateau State, Nigeria (Kaptcheu and Alekwa, 2000), $10.0 \%$ in Jimeta, Yola, Adamawa State, Nigeria (Anogwih, 2011) and $11.0 \%$ in Wolaita Sodo, South Ethiopia; and also lower than those from other parts of Africa (Nkenfou et al., 2013). The difference in prevalence may be due to personal hygienic and sanitary habits of the patients. Also all the patients were partially or totally on ART which signified that they may have been conscious of their low immune conditions. This result was also in conformity with the findings of Bundy and Cooper (1989) and Assefa et al. (2009) that the largest blast of the endemicity of intestinal parasites was heavily entrenched in the developing parts of the world. This result may be attributed to many factors which include poverty, malnutrition, environmental hazards and poor personal hygiene of the people. In general, parasitic infections are an important cause of morbidity and mortality in developing countries, particularly among HIV- positive individuals (Akinbo et al., 2010).

In this study, we found Giardia Intestinalis (22.8\%) to be the most prevalent parasite in HIV positive subjects. This is in conformity with previous studies done in Adama Afar and Dire- Dawa, Ethiopia by Haileeyesus and Bayene (2009), in Jimeta, Yola, Nigeria (Anogwih, 2011) and in Wolaita Sodo, South Ethiopia (Amado et al., 2016) where the parasite was the most common. In contrast, Entamoeba histolytica has been reported as the most common protozoan parasite in HIV infected persons (Ikeh et al., 2006; Udeh et al., 2008; Jegede et al., 2014). Previous studies conducted in Nepal (Sapkota et al. 2004); Iran (Zali et al., 2004); Jakarta, Indonesia (Kurmiawan et al., 2009) had reported Cryptosporidium parvum and Giardia intestinalis as commonest parasites among HIV infected persons as well as in Boringo, Kenya where E. histolytical dispar/moshkovskii and Giardia intestinalis was reported as the most common protozoan parasites (Cornelius et al., 2012); and most of the times were associated with diarrhea. The reasons for these differences in prevalence of these protozoan parasites could be due to the environmental and behavioural pattern of the people in these regions. In the study area for instance, the environment which is a tropical area favours the survival of most cyst of protozoans and ova of other parasitic helminthes. Depressed hosts' humoral immunity also has a significant contributory role in this aspect with special regards to increased susceptibility to Giardial intestinalis. This has been known to occur at a far advanced state of immunosuppression (Robinson et al., 1990) which was in consistent with our study too. The people also have a habit of eating with bare hands which might have been contaminated with ova and/or cysts from the environment. The high propensity of Giardia intestinalis in the present finding suggests that this pathogen is not spread by the anal-oral route or the fecal-oral route. Such transmission is probably secondary to intermittent, sporadic shedding of cysts and that Giardia is predominantly a small bowel pathogen (Ali and Hill, 2003). However, in contrast to other studies from different areas Eucoccidians and Microsporidium parasites were not detected from the stool samples of the patients in this study.

The prevalence of infection was highest in the age group 40-49 years. This result is in line with the findings obtained by Faye et al. (2010); Cornelius et al. (2012) and Yahaya et al. (2013); who reported that prevalence was highest in age group 31-50 years, 20-39 and 40-49 years, 22-40 years and $31-40$ years respectively. This is probably because it is the most sexually active age group. The least prevalence seen in age group 10-19 years could be as a result of reduced immunity which then makes them vulnerable to intestinal parasitic protozoan infection (Rossit et al., 2009). There was no association between respondent's age and parasitic infection $(P>0.05)$.

In this study, intestinal protozoan pathogens were detected more frequently in cases with CD4+ count $<200 /$ cell/ $\mu$ l among HIV/AIDS women patients as in other studies (Assefa et al., 2009; Kurmiawan et al., 2009; Vyan et al., 2012). This may be because HIV patients were either more susceptible to acquire particular parasites and or unable to clear once infection is established. As the duration of HIV/AIDS patients on-ART increases, the prevalence of infections with opportunistic intestinal parasites has been shown to decrease, as reported by other workers (Osmond, 1998; Hansasuta and Row, 2001). 
It is worth noting that the use of HAART has been associated with a gradual reconstitution of the immune system and reduction of HIV associated morbidity and mortality (Hogg et al., 1997).

The significant association of pregnancy status with parasitic protozoan in infected women may be attributed to number of factors; the level of immunosuppressant being paramount. As observed from the results, the higher prevalence of parasitic protozoan among housewives could be due to the fact that most of the participating housewives are nonliterate. This result is similar to that in Biu, Borno State, Nigeria reported by Bello and Olabode, (2011). Evidently, women constitute $70 \%$ of the world's poor and also constitute a large percentage of those infected with HIV. Since women are more vulnerable and lack access to health care, hence more prone to developing parasitic infections.

The prevalence of protozoan infection seems to be higher among patients from the rural area than those from the urban area. This is consistent with the research carried out in Ethiopia (Haileeyesus and Beyene, 2009). This increase prevalence in rural areas could be related to poverty, overcrowding, low levels of hygiene, lack of pipe borne water, promiscuous defecation and un- plastered floors in most of the houses. Also it might be due to the fact that many rural dwellers are more in contact with their domestic animals especially goats, sheep, and dogs, thus

\section{REFERENCES}

Adesiji, Y. O., Lawal, R. O., Taiwo, S. S., Fayemiwo, S. A., Adeyeba, O. A. (2007). Cryptosporidiosis in HIV infected patients with diarrhoea in Osun State, Southwestern Nigeria. European Journal of General Medicine. 4: 119-122.

Akogun, O. B. and Badaki, J. (1998). Intestinal Helminths Infections in two Communities along Benue River Valley, Adamawa State. The Nigerian Journal of Parasitology. 19: 6772 .

Ali, S. A and Hill, D. R. (2003). Giardia intestinalis. Current Opinion in Infectious Diseases. 16: 453-460.

Alo, E. B., Anosike, J. C. and Danburan, J. B. (1993). A survey of Intestinal Helminthes among Students of Post- Primary Institutions in Adamawa State, Nigeria. Applied Parasitology. 34: 161-167.

Alyoune, M. and Biadillah, M. (1991). Atteintes digestives du syndrome de l'immunodéficience acquise (SIDA): mise au point. Medicine du Maghreb. 25: 5-9.

Assefa, S., Erko, B., Medhin, G., Assefa, Z., Shimelis, T. (2009). Intestinal Parasitic Infections in relation to HIV/AIDS Status, and Diarrhoea and CD4 T-cell count. B.M.C Infectious Diseases.9:155.

Akinbo, O. F, Okaka, C. E. and Omoregie, R. (2010). Prevalence of intestinal parasitic infections among HIV patients in Benin City, Nigeria. Libyan Journal of Medicine. 5: 1-6.

Amado, A. A., Wada, W. F., Bisetegn, S. F., Leka, A. Y. (2016). Non-Opportunistic Intestinal increasing their chances of being infected with the parasite. Moreover, most of the patients in the rural areas are farmers who are likely to come in contact with dust containing the protozoan cysts.

In conclusion, the present study had thus confirmed that the overall prevalence of intestinal parasitic protozoan infections in HIV-infected women patients were high despite being on ART. The results also revealed that parasitic protozoan infection is a serious public issue in the study area. Therefore, the need to stress the importance of environmental and personal hygiene as well as provide and monitor the quality of drinking water aimed at obtaining a better quality of life for patients cannot be overemphasize. Routine stool examination should be performed in the followup of female patients with HIV/AIDS attending ART clinics in order to enhance effective treatment of infected patients and other preventive measures. The result of these strategies can reduce mortality and morbidity rates and improve patient's health.

\section{ACKNOWLEDGEMENTS}

The authors would like to thank the ethical committee of Aminu Kano Teaching Hospital, Kano for granting us permission to carry out this study. We appreciate the support and cooperation of laboratory technicians of the hospital for the use of their laboratory equipments and chemicals. We also thank the patients for their interest and cooperation.

Parasitic Infections Among HIV-infected Individuals at WoslaitaScs of opportunistioda Hospital, South Ethiopia. Journal of Coastal Life Medicine. 4(5): 353-357.

Anogwih, J. A. (2011). Intestinal Protozoan Infections in HIV Patients in Jimeta, Yola. Nigerian Journal of Parasitology. 32 (1): 49-54.

Bawa, G. H. (2005). Audit on the Management of Virtual Transmission of HIV/AIDS. Presented in a joint obstetric and pediatric meeting Deter Borough district hospital United Kingdom.

Bello, R. H. and Olabode, H. O. K. (2011). Incidence and Demographic Distribution of Human Immunodeficiency Virus (HIV) in Biu, Borno State, Nigeria. Nigerian Journal of Parasitology. 32 (2): 235-238.

Borle, M., Patil, D. Y. and Sunkoj, Y. (2015). Trends in Prevalence of Opportunistic infection in HIV Infected Children and their correlation with CD4count. International Journal of Science and Technology. 3 (8): 306.

Bundy, D. A. P. and Cooper, E. S. (1989). Trichuris and Trichuriasis in humans. Advance Parasitology. 28: 107-173.

Cheesbrough, M. (2006). District laboratory practice in tropical countries. 2nd ed. District Laboratory Practice. Tropical Countries. Part 2. Cambridge University Press. United Kingdom.

Cornelius, K. K, Robert, S. S., Rose Ogwang, O. (2012). Prevalence of intestinal parasites among HIV patients in Baringo, Kenya. The Pan African Medical Journal.13: 37. 
Faye, B., Tine, R. C., Ndiaye, J. L., Kintega, C., Manga, N. M., Sow, P. S., Gaye, S. (2010). Impact of intestinal parasites on intensity of HIV infection in Senegal. Journal of Antiviral and Antiretroviral. 2(1):11-12.

Fisseha, B., Petros, B. and Wolde, M. T. (1998).Cryptosporidium and other parasites in Ethiopian AIDS patients with chronic diarrhoea. East African Medical Journal. 75:100-101.

Flemings, A. F. (1990). Opportunistic infections in AIDS in developed and developing countries. Transactions of the Royal Society of Tropical Medicine and Hygiene.84:1-6.

Haileeyesus, A. and Beyene, P. (2009). Intestinal protozoan infections among HIV positive persons with and without antiretroviral treatment (ART) in selected ART centres in Adama, Afar and Dire-Dawa, Ethiopia. Ethiopian Journal of Health Development. 23(4):133-141.

Hansasuta P. and Row S. L. (2001). HIV-1 transmission and acute HIV-1 infection. British Medical Bulletin.58: 109-127.

Hogg, R. S., Shaughnessy, M. V., Gatanic, N. B. et al. (1997). Decline in deaths from AIDS due to new antiretrovirals. Lancet. 12: 349:12.

Hunter, G., Bagshawe, A. F., Babso, K.S., Luke, R. and Provic, P. (1992).Intestinal parasites in Zambian Patients with AIDS. Transactions of the Royal Society for Tropical Medicine and Hygiene, 86: 543-54.

Ikeh, E. I., Obadofin, M.O., Brindeiro, B., Baugher, G., Frost, F., Vanderjagt, D \& Glew, R.H. (2006). Intestinal parasitism in Rural and Urban areas of North Central Nigeria: an update. The Internet Journal of Microbiology. 2 (1): 1-12.

Isiodore, A. U., Joanne, E. M., Theo, S. and Myron, A. E. (2009). Potential pathway to HIV/AIDS transmission in the Niger Delta Region of Nigeria. Journal of AIDS Care.12 (5): 567574.

Jegede, F. E., Oyeyi, I. T. E., Bichi, H. Y. A., Mbah, A. H. Kwasi, T. (2014). Prevalence Intestinal Parasites Among HIV/AIDS Patients Attending Infectious Disease Hospital Kano, Nigeria. The Pan African Medical Journal. 17: 295.

Kaplan, J. E., Hu D. J., Holmes, K. K., Jaffe, H. W., Masur, H., De Cock, K. M. (1996). Preventing opportunistic infections in human immunodeficiency virus-infected persons: implications for the developing world. American Journal of Tropical Medicine and Hygiene. 55 (1): 1-11.

Kelly, P. (1998). Diarrhoea and AIDS: recent developments in the African settings. African Health. 1: 16-18.

Keptcheu, D. L.and Elekwa, D. (2000). Prevalence of Intestinal Parasites in HIV Patients in Jos, Nigeria. Journal of Medical Laboratory Sciences. 12:26-29.

Kurniawan, A., Karyadi, T., Dwintasari, S.W., Sari, I. P., Yunihastuti, E., Djauzi, S., Smith,
H.V.(2009). Intestinal Parasitic Infections in HIV/AIDS Patients Presenting With Diarrhoea in Jakarta, Indonesia. Transactions of the Royal Society of Tropical Medicine andHygiene. 103(9): 892-898.

National Population Commission. Census figures of 2006 in Nigeria. National Population Commission, Nigeria (NPC).

OMS (1987). Interrelations entre les maladies tropicales et les infections à VIH: rapportd'une consultation informelle de I'OMS Kenya Medical Research Institute KEMRI: World Health Organization press, 63p.

Okodua, M, Adeyeba, O. A, Tatfeng, Y. M. and Okpala, H. (2003). Age and Sex Distribution of Intestinal Parasitic Infection among HIV Infected Subjects in Abeokuta, Nigeria. Online Journal of Health and Allied Sciences. 4: 3-5.

Olofin, E. A, Nabegu A. B. and Danbazau, A. M. (2008). Wudil within Kano Region. A Geographical Synthesis. A Publication of the Department of Geography, Kano University of Science and Technology, Wudil, pp. 1-52.

Osmond, D.H. (1998). Classification and Staging of HIV Infection. HIV InSite. 1:1-13.

Ramakrishnan, K., Shenbagarathai, R., Uma, A., Kavitha, K., Rajendran, R. Thirumalaikolundusubramanian, P. (2007). Prevalence of Intestinal Parasitic Infestation in HIV/AIDS Patients with Diarrhoea in Madurai City, South India. Japanese Journal of Infectious Disease. 60: 209-210.

Richard, D. and Pearson, M. D. (2016). Overview of Parasitic Infections. (Online), Available from:http://msdmamals.com/home/infection s/parasitic-infections/overview-of-parasiticinfections (Accessed on $19^{\text {th }}$ September, 2017).

Robinson, R. D., Lindon, J. F., Neva, F. A. (1990). Interaction between HTLV-I and $S$. stercoralis infection resulting lower IgE levels in Jamaica. West Indian Medical Journal. 39: 35-37.

Rossit, A. R., Gonçalves, A. C., Franco, C. and Machado, R. L. (2009). Etiological agents of diarrhea in patients infected by the human immunodeficiency. Review of Institute of Medicine of Tropical South Paulo. 51(2): 5965.

Sapkota, D., Ghimire, P., Manandhar, S. (2004). Enteric parasitosis in patients with human immunodeficiency virus (HIV) Infection and acquired immunodeficiency syndrome (AIDS) in Nepal. Journal of Nepal Health Research Council. 2: 9-13.

Shah, U. V., Purohit, B. C., Chandralekha, D., Mapara, M. H. (2005). Co- infection with Cryptosporidium, Isospora and S. stercoralis in a patient with AIDS- a case report. Indian Journal of Medical Microbiology. 21: 137138. 
Sher, A., Gazzinelli, R. T., Oswald, I. P., Clemici, M., Kullbera James, S. L., Morse, III H.C. and Sheaner, G. M. (1992). The role of T-cell derives Cytokines in the regulation of immune responses in parasitic and retroviral infection. Immunological Review.127:183204.

Singh, D. D., Singh, V., Singh, R. and Dwivedi, L. K. (2013). Prevalence of opportunistic intestinal parasite infection in HIV positive population of central India Region. South Asian Journal of Experimental Biology.3 (6) Special: 330- 334.

Teklemariam, Z., Abate, D., Mitiku, H., Dessie, Y. (2013). Prevalence of intestinal parasitic infection among HIV positive persons who are naive and on antiretroviral treatment in Hiwot Fana Specialized University Hospital, Eastern Ethiopia. ISRN AIDS.11:324329.

Udeh, E. O, Goselle, O. N, Popova, D., Abelau, M., Popov, T. V, Jean, N .D. J. (2008). The prevalence of intestinal protozoans in HIV/AIDS patients in Abuja, Nigeria. Science World Journal. 3(3): 1-4.
UNAID/WHO (2013). UNAIDS report on the global AIDS epidemic. Geneva, Switzerland.14.

Vyas, N., Aziz, A. and Nazneen N. (2012). Enteric pathogens in HIV-positive patients with diarrhoea and their correlation with CD4+ Tlymphocyte counts. Tropical Parasitology. 2(1): 29-34.

Weber, R., Bryan, R. T., Owen, R. L., Wilcox, C. M., Gorelkin, L. and Visvesvara, G. S. (1992). Improved high microscopical detection of microsporidia spores in stool and duodenal aspirates. New England Journal of Medicine. 32: 61-166.

Yahaya, A., Tyav, Y. B., Imam, T. S. (2013). Prevalence of intestinal parasitic infections among HIV/AIDS out-patients attending Wudil General Hospital, Wudil, Kano State, Nigeria. International Journal of Pharmacy and Biotechnology. 3: 17-21.

Zali, M. R., Mehr, A. J., Rezaian, M., Meamar, A. R., Vaziri, S., Mohraz, M. (2004). Prevalence of intestinal parasitic pathogens among HIVpositive individuals in Iran. Japan Journal of Infectious Diseases. 57(6): 268-270. 